\title{
Designing Inter Professional Spiritual Health Care Education Program for Students of Health Sciences
}

\author{
Asadzandi $\mathrm{M}^{* 1,2,3,4}$ and Vafadar $\mathrm{Z}^{5}$ \\ ${ }^{1}$ Department of Anesthesiology, Nursing Faculty, Baqiyatallah University of Medical Sciences, Tehran, Iran \\ ${ }^{2}$ Reaserch fellow of Medicine, Quran and Hadith Research Center, Baqiyatallah University of Medical Sciences, \\ Tehran, Iran \\ ${ }^{3}$ Faculty Member of Spiritual Health of the Academy of Medical Sciences of the Islamic Republic of Iran, Tehran, \\ Iran \\ ${ }^{4}$ Founding Member of Spiritual Health Research Center, Qom University of Medical Sciences, Qom, Iran \\ ${ }^{5}$ Department of Surgery, Faculty of Nursing, Baqiyatallah University of Medical Sciences, Tehran, Iran
}

*Corresponding author: Asadzandi M, Department of Anesthesiology, Nursing Faculty, Baqiyatallah University of Medical Sciences, Tehran, Iran, Tel: +98- 9123769064, E-mail: zandi498@yahoo.com

Citation: Asadzandi M, Vafadar Z (2018) Designing Inter Professional Spiritual Health Care Education Program for Students of Health Sciences. J Nurs Patient Health Care 1(1): 101. doi: 10.15744/2767-9292.1.101

Received Date: April 07, 2018 Accepted Date: July 22, 2019 Published Date: July 24, 2019

\begin{abstract}
Background: Spiritual health care requires teamwork and collaboration between the doctor, nurse, psychologist, clergyman, and social worker who have completed required inter-professional spiritual health training, during and after their academic education

Objective: This study was conducted to "design inter professional spiritual health care education program for Students of Health Sciences".

Methods: The "spiritual care model of Sound Heart" designed and validated in 2001-2012. Spiritual problems of patients and healthy clients in communicating with God, self, people and nature was determined. Model-based spiritual care showed positive results in hospitalized patients at acute phase of disease in 2012-2014. Investigating the effect of spiritual care in chronic patients indicates the role of family members as "informal caregivers" in hemodialysis patients in 2016. After considering the need for self-care and home care, based on the spiritual counseling method for patients and healthy clients, spiritual care guidelines were designed and validated. This process resulted in the "Spiritual Empowerment Program" for cancerous children's family. When conducting the survey, it became clear that the spiritual empowerment requires teamwork and collaboration between medical personnel, who need to acquire knowledge, skills and professional competence. Considering the constructs of the spiritual care consulting model of Sound Heart, after adopting appropriate themes and clinically using prominent models, the "inter professional spiritual health care education program" was generated based on previous research findings. It was accredited in two Delphi rounds by ten professors of the Academy of Medical Sciences, including pediatric oncology specialists, psychology, nursing and health education professors.
\end{abstract}

Results: In the first priority, spiritual care is the responsibility of the individual and his family, which requires spiritual empowerment. Clinical implementation of "Family Spiritual Empowerment Program" in spiritual counseling/care sessions, requires understanding the concept and importance of spiritual health, teaching spiritual skills of developing communication with God, self, people, nature, and motivating the family for spiritual self-care. Health science students should be empowered to address patient's spiritual health in a training program using educational technology, multimedia software and a training manual.

Conclusion: Failure to pay attention to the spiritual needs of patients, clients and their families may threaten their psycho-socio-spiritual health and cause spiritual crises. This study suggests that health science students should increase their knowledge, competencies and skills in the area of spiritual care / counseling to meet professional requirements.

Keywords: Inter Professional Education; Spiritual Health; Students; Health Sciences

\section{Introduction}

One of the scientific advances in the third millennium is failure of Descartes' views to include a holistic approach [1]. Descartes considered man as a two-dimensional creature, only including the body and mind in his theory. Descartes believed that the 
science of psychiatry should treat only mental illnesses while medicine should be separate and responsible for the treatment of physical illnesses [2]. In contrast, the holistic approach emphasizes simultaneous attention to all aspects of the human being (biopsycho-social and spiritual problems of health) and introduces man as an integrated whole, consisting of interacting dimensions and indivisible components, whose entire function is not the sum of the component parts [3].

Paying attention to spiritual health as the fourth dimension of health, determining spiritual problems of patients and healthy clients in relation to God, self, people and nature, understanding the impact of spirituality on the treatment of diseases based on the findings of Psycho-Nero-Immune-Endocrinology changing patterns of disease, increasing growth of science, the emergence of new therapeutic approaches and the need to provide multi-dimensional care, are other scientific advances in the third millennium [4-8].

The provision of health services at all levels of prevention using an approach to spiritual health promotion, requires prevention of risk factors, screening, early diagnosis and treatment of spiritual illness in both healthy clients during their growth and development, while considering their ability to self-care and in people who are outpatients, hospitalized, or critically ill patients who have degree of self-care deficiency [9]. Holistic cares have created serious challenges to teamwork and clinical decisions in the collaboration process between different professions [10]. Thus, health sciences students should increase their knowledge about spirituality, how spiritual beliefs affect the lifestyle of clients, and the impact of spirituality on patients' response to disease, and choice of treatment, based on an executive model and collaborative team work [11].

Unfortunately, in the review of literature, there was no pattern for inter-professional spiritual health training courses in Iran. Despite the fact that in 1988, the diagnosis of spiritual distress was accepted in the classification of the North American Nursing Detection Association and today the concept of church nurse is implemented in the United States [12-13]. Still, nurses who provide spiritual care are in the minority, some nurses are not aware of spiritual health and its impact on individual well-being [14]. More than $50 \%$ of nurses, in practice, do not provide spiritual care because they feel they have not acquired the skills, competencies and abilities required to do so properly [15]. Although nurses are aware from the need for spiritual care along with other nursing care, but in practice they do not provide spiritual care because in the nursing textbooks, the spiritual dimension of human existence is not emphasized and there is not enough scientific content in this field [16]. At the bedside, spiritual health care has been repeatedly ignored or in some countries, such as Iran, is provided by some religious leaders [17]. Some nurses and physicians feel reluctant to do spiritual care and feel that spiritual issues are not related to them and are part of the clergymen' work [18].Thus despite the efforts of nursing services; patients' dissatisfaction is due to the oblivion of their spiritual needs [19]. Therefore, it is imperative that employees and students of the health sciences understand spirituality and the importance of spiritual well-being in patients and clients. In Iran's academic education, the necessity of providing spiritual care to patients has been neglected as none of the syllabi have addressed this topic [20]. In clinical centers of Iran, we also see the implementation of the medical care model, while the spiritual distress of the patients remains unknown [21]. Only in severe cases are emotional disturbances referred to a clinical psychologist or psychiatrist. Therefore, this gap in health sciences education and practice should be considered.

Researchers believe that the single-profession education process reduces quality of care provided by health care workers when they are making clinical judgments and decisions during complex real-life situations. This leads to staff experiencing moral distress because they lack having a work environment based on respect and mutual trust [22]. In 1973, the World Health Organization (WHO) warned of the dangers inherent in graduates of health sciences lacking the ability to provide safe and effective teamwork [23]. Then, at the Alma-Ata Summit in Kazakhstan in 1978, the WHO introduced multi-professional training (MIE's) to improve team performance and quality of care. A decade later, after reporting the positive outcomes of "multi-professional education", WHO has introduced the 'inter professional Training' (IPE) as the best new educational approach in preparing health-care students for joint teamwork and providing safe, beneficial, comprehensive, and patient-based care [24,25]. "Inter-professional education" refers to the conditions in which learners of two or more disciplines of health sciences are trained together, in a specific setting and with the goal of engaging and participating in health services for providing effective, client-centered care [26]. This is achieved by fostering among them a sense of collective responsibility, common purpose, language, culture, worldview, and value system [2729].They are prepared and empowered to provide team-based, safe, ethical, comprehensive, integrated care [30].The merits of this approach for learners are: effective communication, conflict resolution, trust, mutual respect, increased understanding of the roles and responsibilities of each discipline, tolerance of differences and limitations, joint targeting based on the needs of clients, and commitment to the common goal [31].

According to the existence of the Soul in man, in the Abrahamic religions and Islam goal of the spiritual care is achieving a Sound Heart (a calm and safe soul, full of trust, love, hope, joy, security, satisfaction, pleasure) [32]. Healthy clients, patients and families are responsible for spiritual self-care. They need to be empowered to take care of themselves [33]. Knowledge and skills, trust, motivation and the development of communication with God, self, people and nature are essential for empowerment of families [34]. Care providers should empower them, thus they must acquire the ability for teamwork by promoting interdisciplinary dialogue during an inter-professional training program [35]. This study was done to "design inter professional spiritual health care education program for Students of Health Sciences".

\section{Methods}

In 2001, seven universal care models were analyzed based on total ratio analysis that is comparable to the perceptual analysis and communication analysis of Carly in nursing [35]. The concept of soul (heart) was derived from the paradigm of Abrahamic 
religions, and the concept of Sound Heart was derived from Quran and hadiths based on the method of adopting concepts [32,36]. Meta-paradigmatic concepts of the model were defined. The spiritual care model of Sound Heart was developed [37]. After designing and validating the "spiritual care model of Sound Heart" in 2001- 2012 and determining spiritual problems of patients and healthy clients in relation to God, self, people and nature [5,38]. Spiritual care guidelines were designed, based on religious and scientific evidence [39,40]. Model-based spiritual care showed positive results in hospitalized patients at acute phase of disease in 2012-2014 [41-44]. Health education models and motivation theories were content analyzed. These models were used in clinical research: including the health belief model with diabetic patients, health promotion in soldiers with high-risk behaviors, and the Precede-proceed model to examine primary sleep disorders in military nurses [45-47]. Investigating the effect of spiritual care in chronic patients indicates the role of family members as "informal caregivers" in hemodialysis patients in 2016 $[48,49]$. Regarding the home-care approach for chronic patients, "Spiritual Empowerment Program" was designed and validated for cancerous children's family [50]. When conducting the survey, it became clear that: the family spiritual empowerment requires teamwork and collaboration between medical personnel, who need to acquire knowledge, skills and professional competence. In this qualitative research, Considering the constructs of the spiritual care consulting model of Sound Heart, after adopting appropriate themes and clinically using prominent models, the "inter professional spiritual health care education program" was generated based on previous research findings. It was accredited in two Delphi rounds by ten professors of the Academy of Medical Sciences, including pediatric oncology specialists, psychology, nursing and health education professors.

\section{Accuracy and reliability of the qualitative data analysis}

The following items were performed to determine accuracy and reliability of the qualitative data analysis: 1-Long-term engagement and continuous observation (Eight stages of research over 16 years) 2-Integration (using nursing care models, health education theories, religious evidence) 3-Peer review (Evaluating and reviewing the research process by scientific experts) 4-Search for contrary evidence(Study about Secular Spirituality) 5- Acceptability of the researcher (Membership in the Spiritual Health of the Academy of Medical Sciences of the Islamic Republic of Iran, founding Member of Spiritual Health Research Center, Qom University of Medical Sciences) 6- Determination (attempting to utilize research results)7-Review by participants (publication of handbooks: A guide to spiritual care for patients. By the Iranian Academy of Medical Sciences, A guide to spiritual care for family. By the Blood and Cancer Research Center of Shahid Beheshti University, Talk to the spiritual caregivers of patients. By Qom University of Medical Sciences) [51].

\section{Results}

According to Yahiya Mel ham, four factors affecting empowerment include:

1. Improvement of knowledge and skills of people

2. Trust and dissemination of power and acceptance of new ideas,

3. Bilateral communication

4. Motivation and attention to the needs of individuals [34].

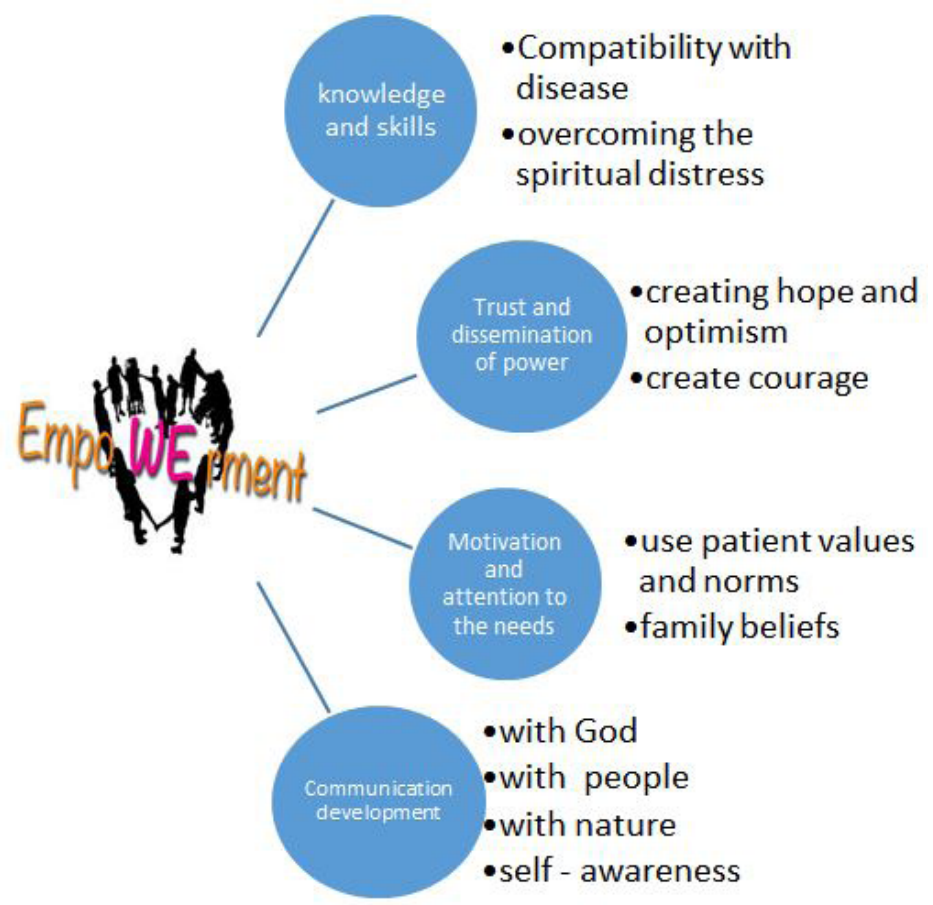

Figure 1: Spiritual Empowerment Factors 
These are in line with the stages of "Family Spiritual Empowerment Program" of the Sound Heart Model.

- Compatibility with disease problems,

- Giving the courage to face crisis of disease,

- Overcoming the spiritual distress,

- Developing the ability of self-care and self-efficacy,

- Motivating,

- Increasing the sense of trust by developing the relationship between patient and family with God, self, people and nature are the main goals of the program. (Figure 1)

Explaining the key competencies and the related skills are the first step for achieving the goals of inter-professional spiritual health education. The doctor, nurse, clergyman, psychologist, social worker should be considered as essential members of the "Spiritual Health Advice Team" [50]. It is necessary to provide team-based and patient-based courses in the inter-professional training course.

\section{Schedule of inter-professional spiritual health training program(Table 1)}

\begin{tabular}{|c|c|c|c|}
\hline $\mathbf{N}$ & Goal; & key competencies: & Related Skills \\
\hline 1 & Improving students' knowledge & $\begin{array}{l}\text { Acquiring knowledge about: } \\
\text {-The need for spiritual care of patients/clients } \\
\text {-The need for inter- professional training } \\
\text { - The importance of spiritual health } \\
\text { - The concept of spiritual health(Sound heart) } \\
\text {-Spiritual Health Indicators } \\
\text {-The characteristics of the perfect man } \\
\text {-Which groups requiring spiritual care? } \\
\text {-When do people need spiritual care? } \\
\text {-what is the principles of spiritual care? }\end{array}$ & $\begin{array}{l}\text { Critical thinking skills } \\
\text { Logical thinking skills }\end{array}$ \\
\hline 2 & Improving students' skills & $\begin{array}{l}\text {-Ability to get spiritual history } \\
\text {-Ability to identify spiritual disorders } \\
\text {-Ability to diagnose family reactions to disease }\end{array}$ & $\begin{array}{l}\text { Assessment skills } \\
\text { Family survey }\end{array}$ \\
\hline 3 & Trust( acceptance of new ideas) & $\begin{array}{l}\text {-How can create courage to deal with the crisis of disease? } \\
\text {-How can achieve Spiritual Health? }\end{array}$ & Problem-solving skills \\
\hline 4 & Communication development & $\begin{array}{l}\text { Applying methods for developing relationships with God: } \\
\text {-for elimination of spiritual vacuum } \\
\text {-for creating hope and optimism }\end{array}$ & $\begin{array}{l}\text { Faith therapy skills (mention of cure, } \\
\text { prayer, touch with healing worship, } \\
\text { surrender, trust in God, assignment } \\
\text { to God) }\end{array}$ \\
\hline 5 & Communication development & Applying methods for developing relationships with people & $\begin{array}{l}\text { Teaching the Skill of: } \\
\text { Patience and Sustainability } \\
\text { Affection and helping others to } \\
\text { please God } \\
\text { Pardon and bless skill } \\
\text { Kindness skill } \\
\text { Amnesty and brotherhood skill } \\
\text { Love Therapy Skill, }\end{array}$ \\
\hline 6 & Communication development & $\begin{array}{l}\text { Acquiring knowledge about: } \\
\text {-Spiritual features of caregivers as a Mentor } \\
\text {-How can create self-efficacy and behavioral intention)? } \\
\text { - Ability to perform spiritual self-care by Daily calculation } \\
\text {-Acquiring knowledge about the cause of various } \\
\text { illnesses and the issue of algebra in divine ordinances } \\
\text {-Teaching methods to adapt to the disease crisis } \\
\text { (emotion-focused adaptation and problem-based } \\
\text { adaptation) }\end{array}$ & $\begin{array}{l}\text { Daily calculation skills } \\
\text { Self-control skills } \\
\text { Self- awareness skills } \\
\text { Skills needed to correct lifestyle } \\
\text { according to illness } \\
\text { Skills for Lifestyle Improvement } \\
\text { Teaching Religious Evidence } \\
\text { Based guidelines of the Sound } \\
\text { Heart Model }\end{array}$ \\
\hline 7 & Communication development & $\begin{array}{l}\text { Applying methods for developing relationships with the } \\
\text { world of creation }\end{array}$ & $\begin{array}{l}\text { Complementary medicine skills: } \\
\text { walking in nature, scenting, listening } \\
\text { to the sound of rain, planting, keep- } \\
\text { ing a pet }\end{array}$ \\
\hline 8 & $\begin{array}{l}\text { Motivation } \\
\text { (attention to the needs of clients/ } \\
\text { patients) }\end{array}$ & $\begin{array}{l}\text { Acquiring knowledge about: } \\
\text {-How can use patient values and norms and family beliefs } \\
\text { for meaningfulness to life events? } \\
\text {-Implementation Spiritual counseling method in clients - } \\
\text {-Implementation of spiritual care in hospitalized patients }\end{array}$ & $\begin{array}{l}\text { Story-telling skill } \\
\text { Comparison and Judgment skill } \\
\text { Practical skills }\end{array}$ \\
\hline
\end{tabular}

Table 1: Schedule of inter-professional spiritual health training program 


\section{Discussion}

The research conducted in 2011, based on “Milles's theorizing approach", examined seven of the most promising models of inter-professional education in the world, namely: the British Columbia University and Dollhouses of Canada, the University of Washington, Franklin and Florida from the United States, Linkoping University of Sweden, and University of Liverpool from England. The results generated three categories: "Conceptual Framework and Scientific Foundations", "Implementation Framework and Educational Interventions" and "Evaluation of Educational Outcomes" [52]. These are in the proposed program and are compatible with the present study.

In the "inter-professional spiritual health training program" conceptual framework and scientific fundamentals are based on "spiritual care model of Sound Heart" [38]. "Implementation framework and educational interventions" are based on the prescriptive model in healthy clients and patients, which has been implemented in numerous studies $[4,9,11]$.

Spiritual care is a fundamental component of holistic nursing practice and determines how people respond to their illness and their associated expectations. The spiritual care model Sound Heart, based on religious spirituality by strengthening the relationship between patient and family with God, can increase the spiritual health of patients and reduce fear and anxiety of the future, the sadness and grief caused by loss of health. It emphasizes on the correction of the four dimensions of human communication (with God, people, self, and nature), emphasis on self-care and home care, encourages the patient's participation in the care, and respects the patient's and family's interests in choosing spiritual care. People with sound hearts live in the light of faith in God, with satisfaction of fate, patience, happiness, optimism, and hope, without fear, future anxiety, regret and sorrow [4].

In the world models, Outcomes are evaluated in three areas: learners, professors and patients with qualitative and quantitative tools [52].In the Sound Heart model "Evaluation of educational outcomes" is based on the characteristics of a perfect human being from a religious point of view [36]. The model has described six attributes for spiritual caregivers / counselors and patients such as: Wisdom, Chastity, Courage, justice, Generosity Kindness, Dignity of soul, Mahmoud position that are in line with the characteristics expressed by "Professor Seligman" [53].

The findings of Vafadar study showed that the goal of "inter-professional education" in the world models were: promoting the socialization process of health science students and the gradual evolution of their identity, by creating extensive inter-professional interactions based on community health needs. With the aim of creating skills and ability to provide teamwork, comprehensive and integrated, based on the needs of the patient and the client, in the graduates of "Health Sciences" [52].

The Sound Heart model, based on the problem-solving method, examines the needs of the patient and the family and determines spiritual diagnosis [5]. Provides training evidence-based guidelines for adaptation to conditions of illness or life stress with pay attention to patient's and family's beliefs and interests [40]. The goal of implementing the model is the family spiritual empowerment for creating courage, hope, and optimism by development of their relationship with God, themselves, people and nature and the training of spiritual skills [49-50].

The research showed that the conceptual framework of universal patterns is based on valid psychological, social, and educational theories. The conceptual framework of the Sound Heart model, based on the Qur'an verses about the "Imitating the prophets as role models" including "Abraham Salam Allah", is in harmony with Albert Bandura's social learning theory. Emphasizes learning based on a "Modeling and Role Modeling" [54]. Model believes that spiritual counselors should be competent for social reform [33].

In the world models, the executive framework focuses on promoting the socialization process of professionals in the form of community-based education. These are in the proposed program and are compatible with the present study [55].It is expected that the findings of this research will be able to familiarize health personnel and health science students with spiritual health care. It is recommended that its effect be investigated in various research centers.

\section{Conclusion}

It is imperative that health care universities pay special attention to human health, the values and beliefs of patients, families and society and provide holistic care based on inter- professional education. In addition to training students of health sciences at the universities, training program of health system staff should also be considered.

\section{Acknowledgments}

We would like to sincerely thank and express appreciation to all professors who collaborated in this study.

\section{Financial Disclosure}

The program is being implemented in a project at the Shahid Beheshti University Blood and Cancer Research Centerwith the Code of Ethics Committee of the University. 


\section{References}

1. Narayanasamy A (2002) Spiritual Coping mechanisms in chronically ill patients. Br J Nurs 12: 1461-70.

2. Asadzandi M (2016) Tehran: Resaneh-takhassosi.

3. George Julia (2007) Nursing Theories, the base for professional nursing practice ( $3^{\text {rd }}$ edition) USA Prentice Hall Com.

4. Asadzandi M (2016) Spiritual counseling. Tehran: Resaneh-takhassosi publication.

5. Asadzandi M (2017) Clients and Patients' Spiritual Nursing Diagnosis of the Sound Heart Model. J Community Med Health Educ 7: 2-6.

6. Sadock BJ, Sadok V (2010) Kaplan and Sadock’s synopsis of psychiatry: behavioralsciences. Clinical Psychiatry. Tehran: Arjmand Publication: 301-26.

7. Barr H, Freeth D, Hammick M, Koppel I, Reeves S (2006) The evidence base and recommendations for interprofessional education in health and social care. J Interprof Care 20: 75-8.

8. Baldwin DC, Baldwin MA (2007) Interdisciplinary education and health team training: a model for learning and service. J Interprof Care 21: 52-69.

9. Asadzandi M (2018) Spiritual health consulting model for health promotion in clients. Health Spiritual Med Ethic J 5: 1-14.

10. Irvine R, Kerridge I, McPhee J, Freeman S (2002) Interprofessionalism and ethics: consensus or clash of cultures? J Interprof Care 16: 199-210.

11. Asadzandi M (2017) spiritual care for patients (A guide book). Tehran: Academy of Medical Sciences of the Islamic Republic of Iran.

12. Carpenito L (2006) Handbook of Nursing Diagnosis ( $8^{\text {th }}$ edn) Philadelphia: Lippincott Williams and Wikins com.

13. Chin L, Kramer M (2004) Integerated Knowledge development in nursing. Mosby patients. Br J Nurs 12: 1470-61.

14. Cavendish R, Konecny L, Mitzeliotis C, Russo D (2003) Spiritual care activities of nursing using nursing intervention classification (NIC) labels. Int J Nurs Terminol Classif 14: 111-20.

15. Mazaheri M, Fallahi Khashkonab R, Madad B, Rahgozar M (2008) Nurses' Attitudes to Spirituality and Spiritual Care. Quart J 8: 31-7.

16. Abdollah KM, Farideh Y, KhodayariFard M, Hamid AM (2013) Developing a measure for assessing oncology nurses' attitudes toward providing spiritual care: psychometric properties. Payesh 12: 393-402.

17. Makhija N (2004) Spiritual coping mechanism chronically ill patients. Br J Nurs 11: 70.

18. Puchalski C, Ferrell B, Virani R, Otis-Green S, Baird P et al. (2009) Improving the Quality of Spiritual Care as a Dimension of Palliative Care: The Report of the Consensus Conference. J Palliat Med 12: 885-904.

19. Harvey IS, Silverman M (2007) The role of spirituality in the self-management of chronic illness among older African and Whites. J Cross Cult Gerontol 22: 205-20.

20. Aboul Ghasemi H, Assadzandi (2018) Strengthening Faith, the main care for maintaining and improving the spiritual health of patients and patients. Journal of Health Promotion. Islamic Republic of Iran Medical Academy 1: 38-49.

21. Tazkari, Valizadeh, Mohammadi, Hassan Khani (2013) Explaining the Process of Learning the Spiritual Care in Iranian Nursing Students - A Study on "Grounded Theory." Journal of Urmia Nursing and Midwifery Faculty 10: 51-62.

22. Baker L, Egan-Lee E, Martimianakis MA, Reeves S (2009) Relationships of power: implications for interprofessional education. J Interprof Care 25: 98-104.

23. Norman I (2005) Inter-professional education for pre-registration students in the health professions: recent developments in the UK and emerging lessons. International Journal of Nursing Studies 42:119-23.

24. Solomon (2010) Interprofessional Education : Has Its Time Come?. Journal of Physical Theraphy Education 24: 3-4.

25. Buring SM, Bhushan A, Broeseker A, Conway S, Duncan-Hewitt W et al. (2009) Interprofessional Education Supplement, Interprofessional Education: Definition ,Student Competencies, and Guidlines for Implementation. Am J Pharm Educ 73: 1-8.

26. Vafadar Z, Vanaki Z, Ebadi A (2015) Barriers to Implementation of Team Care and Interprofessional Education: the Viewpoints of Educational Managers of Iranian HealthSystem. Iranian Journal of Medical Education 14: 943-56.

27. Bennett PN, Gum L, Lindeman I, Lawn S, McAllister S et al. (2011) Faculty perceptions of interprofessional education. Nurse Educ Today 31: 571-6.

28. Elisabeth C, Ewa P, Christine W-H (2011) The team builder: The role of nurses facilitating interprofessional student teams at a Swedish clinical training ward. Nurse Educ Pract 11: 309-13.

29. Haidet P, Fecile ML, West HF, Teal CR (2009) Reconsidering the team concept: Educational implications for patient-centered cancer care. Patient Educ Couns 77: 450-5.

30. Sherwin S (2009) Interprofessional working is key to delivering quality PSHE. British Journal of School Nursing 4: 93-5.

31. Thistlethwaite J, Moran M (2010) Learning outcomes for interprofessional education (IPE): Literature review and synthesis. J Interprof Care 24: 503-13.

32. Asadzandi M (2014) Access to the Sound Heart identifies the concept of spiritual health. J Med Jurisprud 6: 143-73.

33. Asadzandi M (2017) Spiritual self-care. Tehran; Resaneh-takhassosi publication, Iran.

34. Melhem Y (2004) The antecedents of customer-contact employees' empowerment. Employee relations 26:72-93.

35. Larijani B (2015) Evolution and Innovations Packages in Medical Education Based on Higher Education Awareness Program.Tehran: Ministry of Health and Medical Education, Islamic Republic of Iran,P: 73-8.

36. Asadzandi M (2001) Critique of Nursing Models at the Level of Applied Concepts and Equations and Model Designing [PhD thesis]. Faculty of Health, Baqiyatallah University of Medical Sciences, Iran.

37. Asadzandi M (2017) Professors, spiritual characteristics for role- modeling education. Educ trateg Med Sci J 10: 23-35.

38. Asadzandi M (2014) Analysis of nursing concepts and theories with introduce Sound Heart model. Tehran: Publication Hydrae 250-6.

39. Asadzandi M (2015) Sound Heart: Spiritual Nursing Care Model from Religious Viewpoint. J Relig Health 54:130-145.

40. Asadzandi M, Eskandari A, Khademolhosseini SK, Ebadi A (2017) Designing and Validation Islamic Evidence-Based Spiritual Care Guidelines of Sound Heart Model in the Dying Patients. Journal of Medical Sciences 10: 1-6.

41. Asadzandi M, Eskandari A, Khademolhosseini SK, Ebadi A (2018) Designing and validation religious evidence-based guidelines of Sound Heart pastoral care model for hospitalized patients. Journal of Medical Sciences 1: 1-9. 
42. Asadi M, Asadzandi M, Ebadi A (2014) Effects of spiritual care based on Galba Salim nursing model in reducing anxiety of patients undergoing CABG surgery. Iran J Critical Care Nurs 6: 142-151.

43. Saeidi- Taheri Z, Asadzandi M, Ebadi A (2014) The effect of spiritual care based on Galba Salim model on the sleep quality of the patients with coronary artery disease. IJPN 7: 94-103.

44. Asadi M, Asadzandi M, Ebadi A (2014) The effect of spiritual care based on Galba Salim model on spiritual experiences of patients undergoing coronary artery bypass surgery. Journal of Cardiology 2: 67-73.

45. Saeidi Taheri Z, Asadzandi M, Ebadi A (2013) The effect of spiritual care based on Galba Salim model on spiritual experience in patients with coronary artery disease. IJPN 1: 23-34.

46. Farsi Z, Asadzandi M, Najafi S (2010) Application of Health Belief Model in Change of Self Care Behaviors of Diabetic Patients. IJN 22: 61-7.

47. Asadzandi M, Sekarifard M, Ebadi A, Morovvati Sharif Abad MA, Salari M (2014) Effects of anger management training based on Health Promotion Model on soldiers engage in risky behavior. Iranian Journal of Psychiatric Nursing 2: 68- 79.

48. Sayari R, Asadzandi M, Sanayi Nasab H, EbadiA (2018) Journal of Psychiatry and Behavioral Health Forecast 1(1): 1-6

49. Akbarpour Mazandarani H, AsadzandiM, Saffari M, Khaghanizadeh M (2017) Effect of Spiritual Care Based on Sound-Heart Consulting Model (SHCM) on Spiritual Health of Hemodialysis Patients. Iran J Critical Care Nursing 10: 1-6.

50. Mazandarani H, AsadzandiM, Saffari M, Khaghanizadeh M (2018) The Effect of Spiritual Care Based on Sound Heart Model on Quality of Life in Hemodialysis Patients. J Psychiatry Behavior Health Forecast 1: 6-12

51. Shahrabee S,Asadzandi M, EbadiA (2017) Effect of self-care empowerment program by multimedia on the level of spiritual health and caring stress in the cancerous children's family. Master's thesis for children's nursing. Faculty of Nursing, Baqiyatallah University of Medical Sciences

52. Streubert C (1990) Qualitative research in nursing (advancing the humanistic imperative). Philadelphia: Lippincott com.

53. Vafadar Z, Vanaki Z, Ebadi A (2016) An Overview of the most Prominent Applied Models of Inter-Professional Education in Health Sciences in the World. Rme 8: 69-80.

54. Asadzandi M (2018) A guide to spiritual care for the family of patients. Tehran: Resaneh-takhassosi

55. Safari M, Shojaeizadeh D, Ghofranipour A, Fazlullah M, Heidarnia AR (2012) Theories, models, methods of health education and Health Promotion. Tehran: Siobhan.

56. Asadzandi M (2017) Talk with spiritual advisers and spiritualists. Publisher: Resaneh-takhassosi.

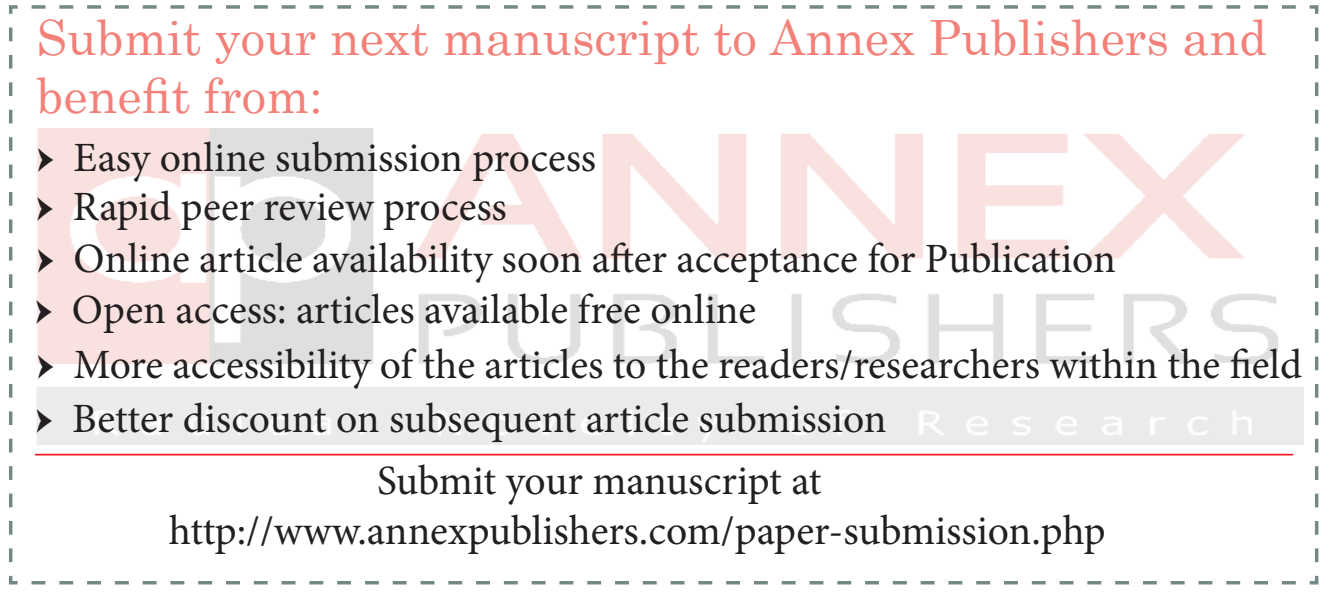

